\title{
An electron microscope study of molluscum contagiosum*
}

\author{
BY ARWYN CHARLES \\ Departments of Dermatology and Biomolecular Structure, The University, Leeds
}

(Received 15 September 1959)

\section{INTRODUCTION}

The mildly infective virus of molluscum contagiosum belongs to the pox group of viruses, and, with psittacosis, is one of the largest viruses capable of infecting man (Lever, 1954). It has been observed electron microscopically in thin-sectioned material by Banfield, Bunting, Strauss \& Melnick (1951, 1952), and Melnick, Bunting, Banfield, Strauss \& Gaylord (1952), but their use of formalin fixation and removal of the methacrylate embedding material from their sections are unsatisfactory for the preservation of fine structural detail. Gaylord \& Melnick (1953), using more acceptable techniques, also observed the virus, but their published observations were rather cursory and intended only for comparison with their more informative examination of the vaccinia and ectromelia viruses.

The work of Morgan, Ellison, Rose \& Moore $(1954 a, b)$ on the viruses of herpes simplex, vaccinia, and fowl pox, however, was a marked advance from which a very clear picture began to emerge of the early stages of virus development.

The present paper is intended to show more fully the development stages of the molluscum contagiosum virus, and to compare them with those of the vaccinia and fowl pox viruses as described by Morgan et al. (1954b), to which they are very similar. The accompanying changes of the epidermal cells, leading to the formation of the molluscum body, will also be shown.

After this paper had been drafted I became aware of the paper by Wada (1957), and the further report of Banfield (1958). I have so far been unable to see Wada's paper, and I am unaware of any further publication by Banfield. $\dagger$

\section{MATERIAL AND METHODS}

Molluscum lesions were obtained from two children, a girl aged 13 years and a boy aged 12, and a 41-year-old woman.

The girl's lesion $\ddagger$ was removed from the neck, and was the youngest looking of a group in which the first lesion had appeared about 6 months previously. In the boy the lesion, of not more than 2 months' duration, was removed from the chest without anaesthesia; in the adult the lesion, of 6 months' duration, was scraped from the lower eyelid.

* This paper forms part of a thesis presented for the degree of Ph.D., University of Leeds, October 1958.

$\dagger$ See supplementary note at foot of p. 53 .

‡ This lesion appeared to be compound, that is, several mollusca had developed within the single lesion. 
Except for the boy, local anaesthesia was induced with $2 \%$ procaine containing $1: 40,000, \mathrm{w} / \mathrm{v}$, adrenalin to reduce bleeding.

The lesion was then placed on a cork slightly moistened with veronal buffer, and cut into small pieces with a razor blade. These pieces, some about $1 \mathrm{~mm}$. cube and others rather larger, were transferred to chilled $1 \%$ osmium tetroxide made

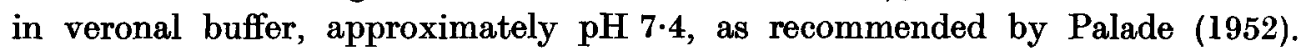
Fixation commenced about $7 \mathrm{~min}$. after injection of the anaesthetic and continued for $2 \mathrm{hr}$. in the refrigerator, being completed by standing for another $2 \mathrm{hr}$. at room temperature.

After washing and dehydration to absolute ethyl alcohol pieces of material were infiltrated with $n$-butyl methacrylate monomer containing $1 \%$ benzoyl peroxide, or with 'Araldite' epoxy resin as recommended by Glauert, Rogers \& Glauert (1956) and Glauert \& Glauert (1958).

The methacrylate infiltration was in the usual manner, and embedding was carried out at $60^{\circ} \mathrm{C}$. according to the recommendation of Borysko (1956) but in a monomer-polymer mixture of slightly syrupy consistency. Such a mixture appears to have no special virtue, and was later discontinued.

The Araldite infiltration was carried out by standing for $1 \mathrm{hr}$. periods in $1: 1$ and 1:3 mixtures of absolute alcohol and Araldite at room temperature, followed by two $1 \mathrm{hr}$. changes of pure Araldite at $60^{\circ} \mathrm{C}$.

So far the accelerator component had not been added to the Araldite mixture, but the tissue was now placed in a mixture containing accelerator and allowed to infiltrate for $1 \frac{1}{2} \mathrm{hr}$. at $60^{\circ}$. It was then transferred to a foil boat (Borysko, 1956) containing fresh Araldite plus accelerator and allowed to stand at room temperature overnight. Polymerization was completed by leaving at $60^{\circ}$ for the following day.

\section{RESULTS}

Owing to the bowl-like shape of the molluscum lesion, formed by proliferation of the epidermis, there is no difficulty in orienting the material for sectioning in such a way as to be able to follow the development stages of the molluscum body. The lower, convex, part of the lesion shows uninfected, or relatively uninfected, cells which become progressively infected as they approach the inner, concave, part, where the molluscum bodies and accompanying normally cornifying scales are shed.

With the exception of Pl. 5, fig. $8 \mathrm{~B}$, the following account will be illustrated wholly from the adult lesion. The epidermal cells of the children's lesions appeared to react more vigorously to the virus, and the cytoplasm was invariably oedematous. As a consequence the viral particles seem to develop imperfectly, showing an absence of central viroplasm.

\section{Development of the molluscum body}

Although the lowermost cells of the lesion, next to the dermis, are not observably infected, they are nevertheless of abnormal appearance. Part of such a basal cell is shown in Pl. 1, fig. 1, and the great increase in cytoplasmic detail becomes obvious when the cell is compared with a normal epidermal cell (see Selby, 1955; 
Charles \& Smiddy, 1957). There is present much particulate and vesiculate material, occasional unidentifiable structures one of which (x.a.) is shown, and a structure of more consistent appearance to which the description 'membranous structure', or 'double-membrane structure', is given. This consists (Pl. 4, fig. 7D) of a double limiting membrane usually enclosing coarse granular material. The mitochondria are relatively large, much increased in number, and generally appear to be slightly swollen. In Pl. 1, fig. 1, only one very swollen mitochondrium is seen, the majority of them being located below the level at which the figure terminates. The interdigitating wall-membranes of adjacent cells are seen, and are generally more orderly in their arrangement than is illustrated. Upon them prickles (or desmosomes) are seen to form, which appear to rupture very readily. Prickle breakage (b.p.) of this kind is readily observable in pathological epidermis, and may be ascribable to the action of inflammatory intercellular fluids; that there is such an exudate is suggested by the intercellular debris discernible in parts of the tissue.

The first appearance of the virus is observable in Pl. 2, fig. 3. The finely dispersed cytoplasm, called the cytoplasmic cloud for convenience, shows the appearance of partial viral membranes at its periphery, a mode of virus development previously illustrated by Morgan et al. (1954b). The mitochondria are greatly swollen and tend to be arranged around the periphery of an area of cytoplasm (u.c.) differing in appearance from the much-vesiculated cytoplasm at the bottom of the figure; some fibrous material is shown. In the vesiculated cytoplasm occur two regions having the typical Golgi appearance to which, because of the pathological condition of the cell, the name Golgi-type structure is given. As a matter of observation Golgi structures, or Golgi-type structures, are seen far more readily in pathological epidermal cells than in normal; in one micrograph a Golgi-type structure was seen to extend for a distance of $40 \mu$ alongside the nucleus.

The nucleoplasm shows intra- and extra-nucleolar vesiculation, and the presence of dense bodies which can generally be found in advance of the appearance, or at least the readily detectable appearance, of viral particles. It is noticeable on the original micrograph, though not from this enlargement, that even at this comparatively early stage of infection the nucleus is located very much to one side of the cell.

Pl. 3, fig. 5, shows advanced infection of the cytoplasm. The nucleus is very abnormal and appears to contain, rather unusually, protoplasmic 'clouds' of its own; the much indented nature of the nucleus makes it possible that these are in fact cytoplasmic.

The cytoplasmic cloud is here considerably larger than in the previous figure, and shows abundant evidence of virus development. Advanced viral particles are located chiefly at its periphery, but in Pl. 4, fig. $7 \mathrm{~A}$, viral development spreads inwards to the centre, leaving a well-defined cytoplasmic region free of viral particles to line the cell. The structure of virus particles through a wide range of development can be seen, and will be considered in detail later.

The nucleus shows no sign of further deterioration; indeed, although it always shows signs of abnormality and is generally pushed to one side of the cell as the virus develops, there is no evidence that the virus ever destroys the nucleus. 
Pl. 1, fig. 2, shows the mature molluscum body surrounded by the scales of normally cornified cells. The body is at the stage of being shed into the centre of the molluscum lesion; subsequent changes lead to the complete obliteration of the details seen here.

The original epidermal cell is now quite tightly packed with viral particles showing some slight variation in shape and size. Cytoplasmic remains, imbedded with virus, are seen at the centre and lining the periphery, while the nucleus is also easily recognizable. The dense bodies previously seen in the nucleus are not recognizable with their former clarity, but on the original micrograph it is possible to detect denser spots which may or may not be the structures originally seen so clearly.

So far as can be judged from electron micrographs this nucleus may still be capable of some viable activity. It is not obviously different in appearance from a nucleus of a normal cell of the same age, in which it would, of course, be disorganizing in the process of cornification (Charles, 1959).

The apparently rare occurrence of extracellular viral particles suggests that the peripheral cytoplasm forms on the whole a very effective container for the enclosed virus mass. Of much interest are the grains (v.p.) imbedded in the horny scales; presumably these are occasional viral particles occurring in normal-looking, 'uninfected', cells from which the scale was formed.

The occurrence of normally cornifying cells between infected cells is easily observable because the normal cells contain keratohyalin, as shown in Pl. 2, fig. 4. Frequently the cytoplasm of the 'normal' cell is reminiscent of that shown by cells in the early stages of infection described above. This may be because the normal cell, now beginning to cornify, has a decreased resistance to the virus, or because it has had to fight infection throughout its life. In Pl. 2, fig. 4, the vesiculate structures present in the peripheral cytoplasm of an infected cell are readily distinguishable.

\section{Development of the virus particle}

In the preceding description of the formation of the molluscum body the concurrent stages in the formation of the virus have been shown without being particularly remarked upon.

Pl. 5, fig. 8A, is an enlargement of the central part of Pl. 4, fig. $7 \mathrm{~A}$, and shows a number of stages of virus development. Stage 1, marked on the figure, shows the first certain appearance of the virus, emerging from the general background of cell cytoplasm as a 'ghost' of viroplasm (Morgan et al. 1954b). Similar stages taken from another section are shown enlarged in $\mathrm{Pl}$. 5, fig. $8 \mathrm{C}$, in the original of which are descernible darker spots (nd.) suggestive of the first appearance of the nucleoid. The size of the virus particle remains essentially constant throughout its development from 'ghost' to maturity. The ellipsoid-shaped particles seem to vary in size between 280 and $200 \mathrm{~m} \mu$ for the long axis, and 170 and $130 \mathrm{~m} \mu$ for the short; the rarer globoid particles have a diameter of about $200 \mathrm{~m} \mu$.

Stage 2 shows the partial formation of a membrane around the viroplasmic 'ghost'. It is difficult to be certain whether the partial nature of this membrane 
is fact or artifact, a result of sectioning damage; in case of the virus particle at (c) in Pl. 5, fig. $8 \mathrm{~A}$, for example, obviously advanced yet only partially enclosed by its substantial membranes, the explanation must almost certainly be cutting artifact.

Stage 3 shows the complete enclosure of the viroplasm by the membrane, and this stage is shown enlarged from another section in $\mathrm{Pl}$. 5, fig. 8D. Here is shown a well delineated, denser, nucleus-like region, or nucleoid (Morgan et al. 1954b), which soon becomes silhouetted from the rest of the viroplasm by a clearer region (Pl. 5, fig. 8E). Stage 4 shows the increasing density of the central viroplasm, tending to leave a clearer marginal area between it and the membrane; the nucleoid is still present.

Stage 5 shows the continued density increase of the central viroplasm, and stage 6 the splitting of the outer membrane (Morgan et al. 1954b) to form a double membrane.

Particle $(b)$ is unusually cut and appears very much like a particle of herpes simplex shown in Pl. 10, fig. 5, of the paper by Morgan et al. (1954a). A quarter of the capsule wall has been removed showing the enclosed central body which is rather denser than the peripheral viroplasm.

The denser granular material ( $g . m$.) seen in this and other figures does not appear to have any significance; certainly it does not seem to be the equivalent of the very fine, dense material which so clearly forms the nucleoids of the fowl pox virus, as shown by Morgan et al. (1954b).

Pl. 4, fig. 7B, is an enlargement illustrating later stages of virus development. There are essentially two further stages, stage 7 showing the double outer membrane, with the central viroplasm now looking very much like a nucleus consisting of a lighter centre bordered by a denser, irregularly disposed, periphery, the whole being separated from the external double membrane by a light area of viroplasm. This particle is enlarged in $\mathrm{Pl}$. 4, fig. $7 \mathrm{C}$, and its square outline indicates that it is a brick-shaped particle so common in dried virus extracted from the cell (Green, Anderson \& Smadel, 1942).

One wonders at this stage whether the denser peripheral material of the viroplasmic 'nucleus' bears any relationship to the nucleoid which, it would seem, dispersed, or disappeared, at stage 5. Certainly the central viroplasm has been consistently differentiated from the outer from quite an early stage, but the behaviour of the nucleoid in the central viroplasm is unclear.

Stage 8 shows the fusion of the two outer membranes into a single capsule wall the thickness of which equals the space occupied by the original two membranes; occasionally there is seen a sectioned virus particle which seems to have two double membranes, suggesting that an inner single membrane also becomes, or can become, split. This inner double membrane is not easy to see, but its presence is in agreement with the structure of the vaccinia virus (Peters, 1956).

Various other appearances of the virus have been seen: Pl. 4, fig. $7 \mathrm{E}$, shows the virus with an outer membrane enclosing an inner one in which are two particulate bodies; sometimes the inner membrane and its contents are replaced by a single central body, but this is not illustrated; Pl. 4, fig. $7 \mathrm{~F}$, shows the central viroplasm 
enclosed in a membrane and dumb-bell shaped in section (Gaylord \& Melnick, 1953). This shape is explained as being due to the disk-like shape of the inner body (Morgan et al. 1954b; Peters, 1956).

Pl. 4, fig. $7 \mathrm{G}$, shows a virus particle very different in construction from those previously illustrated. It may be described as a double-membrane structure (Pl. 1, fig. 1) surrounded by a peripheral region of viroplasm delineated by a membrane. This kind of particle is seen much less frequently than the other already described in detail; in Pl. 5, fig. 8A, one such particle is seen at $(a)$, where the limiting membrane of the outer viroplasm is vaguely discernible, and the inner double-membrane containing the granular central viroplasm appears solid either because it has not been resolved by the microscope or because it has fused into a single thick wall. Pl. 5, fig. 8B, shows the hollow, empty nature of the virus found in the lesions removed from the two children.

Pl. 3, fig. 6, is an enlargement of a nucleus containing dense bodies, indicated by arrows; the nuclear membrane and the nucleolus are also shown. Although the development of the dense bodies, or at least their increase in size, can be traced from the early stages, there is no evidence of any especially organized development, the process appearing to consist only of a clumping of particulate material.

\section{DISCUSSION}

It is clear from the above observations that the development of molluscum contagiosum virus is very similar indeed to that of vaccinia and fowl pox, described by Morgan et al. (1954b), and it is clear also that there occur certain differences. Much of the following discussion will be concerned with the comparison and contrast of the present work with theirs, and unless otherwise stated the remarks will refer to their publication $(1954 b)$.

The molluscum virus is more akin to fowl pox than to vaccinia in its development from definite foci, single or multiple, of finely dispersed cytoplasm called here cytoplasmic clouds. It is more akin to vaccinia than to fowl pox in that there is no evidence of a denser, finely granular, pre-nucleoid material: the only time the denser nucleoid material is seen in the development of the molluscum, as in the vaccinia, virus is in the actual nucleoid. Possibly the nucleoid increases in density as it matures (P1. 5, figs. 8C and D), but this is uncertain.

In their account of the development of vaccinia and fowl pox viruses, Morgan and his colleagues make no mention of any nuclear changes being observed as infection becomes established. In the case of molluscum contagiosum, however, the appearance of the virus in the cytoplasm of the cell is preceded by the formation of dense particulate bodies in the nucleus. These bodies show no especially organized development, but appear to form by simple clumping of particulate material; one wonders whether it is chromosomal material. Their increase in the nucleus stops quite early, and although the nucleus tends to be abnormal in showing also vacuolation of the nucleolus and of the non-nucleolar nucleoplasm, it is not destroyed, being easily recognized even in the fully developed molluscum body. Here, as in the two viruses investigated by Morgan $e t$ al., there is no evidence of virus development in the nucleus. 
The molluscum contagiosum virus particle develops a stage further than the vaccinia and fowl pox viruses, because in the oldest stages shown by Morgan et al. for these two the outer membrane remains double. In the molluscum virus, however, the double membrane ultimately fuses into a single capsule wall, the two-membrane origin of which can sometimes be detected in section. The central core of the molluscum virus is sometimes seen to be enclosed in a double membrane, which parallels the structure of vaccinia described by Peters (1956).

It is easy to agree with Morgan and his colleagues, that these double membranes most probably arise by splitting of the original single membranes, because no development stages of the second membrane have been observed: it is either not present at all, or there are present two membranes of identical appearance. It also seems reasonable to agree that the cytoplasmic clouds are sites of origin of the virus, rather than of its dissolution. The clarity of their electron micrographs showing partial membranes forming around the developing viroplasm leaves little doubt of the real existence of such membranes. I have seen much the same thing at the periphery of the cytoplasmic cloud, but as the cell ages and virus development tends to encroach on the centre, and not to be confined to the periphery, of the cloud, I feel that, as a consequence, the development of the viroplasm becomes more symmetrical, and apparently-partial membranes may then most often be artifacts of the cutting process.

Regarding the nucleoid, which is possibly detectable at stage 1 , and disappears after stage 4 (Pl. 5, figs. 8A, C, D and E), it is possible to interpret its behaviour in a manner differing from that of Morgan et al. Their figures show nothing of the separation of a central mass of viroplasm, in which the nucleoid is embedded, from a less dense peripheral region (PI. 5, fig. 8A). Consequently they assume that the central core or body of their most mature virus is the expanded nucleoid, whereas it could, more correctly I feel, be considered to be the originally separated central mass throughout which the nucleoid has dispersed. It may rightly be argued that the interpretation of Morgan et al. is correct, and the alternative suggestion arises only because of dehydration effects which have contracted the central viroplasm away from the enclosing membrane. One may doubt, however, whether the membrane at stage 4 would be rigid enough to permit differential contraction of this kind, especially when Pl. 5, fig. 8D, which is a stage of development only slightly earlier than stage 4, does not show it; this Araldite-embedded material accompanied the methacrylate-embedded material of Pl. 5, fig. 8A, through the alcohols. It is doubtful also whether it is an embedding artifact because the virus particle at stage 7 ( $\mathrm{Pl} .4$, fig. $7 \mathrm{~B}$ or $\mathrm{C}$ ) is identical with the extracellular viral particles shown by Morgan et al. in their Pl. 39, fig. 14. This late form has been seen in the present paper to develop stepwise from the earlier form, whereas Morgan et al. show no stages between their small eccentric nucleoid and the larger central body to which they say it expands. Indeed the two lower particles in their Pl. 39, fig. 14 suggest that the dense nucleoid material is dispersing through the large centrally situated viroplasm of intermediate density, a process agreeing with the interpretation here preferred.

Morgan et al. (1954a) emphasize that they could offer no information 'concerning 
the stage of viral development at which the attribute of infectivity is acquired', and mention the possibility that a virus-free peripheral zone of the mesodermal cells, in the body of which cells the virus develops, may have acquired some defensive mechanism against the virus. These problems are not especially illuminated by my own work. The very abnormal appearance of the lower epidermal cells of the molluscum lesion, in which no virus was seen, has been remarked upon (Pl. 1, fig. 1), and it is possible that this was a pre-infection stage, that is, a stage where viral infection cannot be observed but where protoplasmic changes are taking place prior to observable infection. Such stages were not described by Morgan $e t a l$., but the conditions attending their experimental inoculations are different-more 'sheltered' and of lesser duration-from those experienced by naturally acquired lesions on the human body, which formed the illustrative material for this paper. The evidence of possibly inflammatory oedema in the material is a warning that the early cell changes described here may be due to this cause, and not to pre-morphologically-observable viral effects.

Normally-cornifying epidermal cells are frequently sandwiched between infected cells, and it is not unusual for the cytoplasm of the 'normal' cell to show the abnormalities found in young pre-infection cells. Normal cells sandwiched in this way must constantly be in close contact with any infective element of the virus, and this may explain the presence of a few virus-like particles detectable in the 'normal' horny squames in Pl. 1, fig. 2.

Morgan et al. (1954a) ascribe the oval shape of their virus particles to the impact of the knife during the cutting process, which would compress the specimen block and distort globoid virus particles into ellipsoids. Pl. 5, figs. 8C and D show that this need not occur, and Pl. 1, fig. 2, and Pl. 4, fig. $7 \mathrm{~A}$, make it difficult to relate particle shape to direction of cut. Presumably the virus in this material has been shaped by the compressions and buffetings of everyday life, and would understandably contrast with the viruses of Morgan $e t$ al. which had a more sheltered upbringing.

The probable presence of a second type of virus particle, the appearance of which strongly suggests that it is derived from, or is related to, the double-membrane structure, as illustrated in Pl. 1, fig. 1, and Pl. 4, fig. 7D, is a complication of unknown significance. It would be extraordinary if the double-membrane structures were virus 'nuclei' awaiting the formation of a viroplasmic periphery: this would be the reverse of the usual procedure where the centre is formed by consolidation of the original globule of viroplasm. Possibly it could be argued that the double-membrane structure represents the remains of this second type of virus after it has been attacked by the cell and the peripheral viroplasm destroyed. However, there can be no question that, with its single outer membrane, light peripheral viroplasm, inner double membrane, and coarsely granular centre, this second virus differs substantially from the more usual type.

The molluscum body shown in Pl. 1, fig. 2, undergoes further change, not illustrated in this paper, in which it and the accompanying normally cornifying horny layers become 'fully cornified'. Virus particles, cytoplasmic strands, and nuclear remnant then all disappear to form what appears in the electron microscope as a structureless 'keratin'. It is a point of interest that the contents of the body 
can ultimately degrade into so homogeneous-looking a material, which, however, is less electron-dense than the enwrapping layers derived from normal cells. Mescon, Gray \& Moretti (1954) have shown that histochemically the mature molluscum body and normal horny layers react very differently.

\section{SUMMARY}

The development of the molluscum body and of the molluscum contagiosum virus is described. All cells of the molluscum lesion do not form molluscum bodies, but those which do probably show cytoplasmic abnormality prior to the appearance of virus particles within the cytoplasm. Such abnormal cells may reflect the activity of some infective precursor of the morphologically observable virus particle; they may alternatively represent cells which have successfully resisted invasion by the infective precursor.

Cells which have failed to resist invasion gradually become filled with virus particles and the nucleus becomes eccentric. The molluscum body thus formed is virtually a bag of virus particles, the wall of the bag being the peripheral cytoplasm, which seems to resist invasion and in which the nucleus remnant can readily be detected.

There appear to be two kinds of viruses. Development of the commoner virus is compared and contrasted with studies by Morgan and his colleagues of vaccinia and fowl pox. It is akin to fowl pox in its origin from foci of finely dispersed cytoplasm, here called cytoplasmic clouds; it is akin to vaccinia in that no evidence can be found of a denser, finely granular, pre-nucleoid material; it is like both in that the virus does not observably develop within the nucleus; and it is unlike both in that a nuclear change - the appearance of rather unspecific dense bodiesis seen. The structural changes seen in the virus particles during development are similar to those described by Morgan et al., but a slightly different interpretation is given of the behaviour of the transient 'nucleoid' : they believe that it expands to form a central viroplasm, whereas in this paper it is believed to disperse through an already present central viroplasm.

The second type of virus is of uncertain origin. It may develop from, or at least it seems to be related to, a double-membrane structure seen in abnormal lesion cells.

\section{Note added since paper was prepared for publication*}

Two very full accounts of molluscum contagiosum have, however, now appeared, by Banfield \& Brindley (1959), and by Dourmashkin \& Bernhard (1959), the latter of which has illustrations of exceptional quality; in these papers the reader will find references to earlier work of which the present writer regrettably was ignorant (Takaki, Suzuki, Yasuda, Taguchi, Dohi \& Sasao, 1957; Dourmashkin \& Febvre, 1958; Dourmashkin \& Duperrat, 1958; Banfield, 1959).

The observations and views given in the present paper seem to agree more closely with those of Dourmashkin \& Bernhard than those of Banfield \& Brindley. The dense material mentioned in both these papers, called 'free nucleoid' material

* See p. 45, Banfield $\dagger$. 
by Dourmashkin \& Bernhard, is appreciably more characterized than its equivalent-the 'granular material'-in the present paper. This material I considered too coarse to be likened to the pre-nucleoid material of Morgan et al. (1954b), and the 'free nucleoid' material likewise seems coarser than the material of Morgan and his colleagues, and not so well related to nucleoid formation. Nevertheless, the 'granular material' aggregates in the same way as the 'free nucleoid' material (see Pl. 3, fig. 5), and the opinion expressed in this paper, that pre-nucleoid material is absent, may well prove to be wrong.

The double-membrane structure (called ' $\mathrm{C}$ body' by Banfield \& Brindley) is thought by Dourmashkin \& Bernhard to be derived from a mitochondrium; this is not the view I favour, especially as they do not mention the presumed second type of virus. It must be said, however, that on one occasion I have seen this structure in skin from a patient not suffering from molluscum contagiosum; it was a solitary example in a solitary cell.

In order to form some opinion on the dense body reported by Banfield (1959), I have re-examined about 100 electron micrographs. Three plates, showing mature virus, provided good evidence of this body. As in Banfield's illustration, its position within the viral particle was haphazard; furthermore, it seemed to occur far more frequently in the section than would be expected statistically, and on one plate most of the viral particles had multiple, up to six, bodies. On other plates not a single example of it could be found among hundreds of particles. Consequently I find it difficult to convince myself that this body is a real structure.

A final remark concerns the 'hollow' virus particles (Pl. 5, fig. 8B). Both Banfield and Dourmashkin and their colleagues regard this as a definite stage in the development of the virus. I regard it as a reflexion of the oedematous reaction of the cells to the virus, because I saw no evidence of such a stage in the material taken from the adult.

I am grateful to Prof. W. T. Astbury, F.R.S., for reading and improving the original draft of this paper.

\section{REFERENCES}

BANFIELD, W. G. (1958). Electron microscope studies of molluscum contagiosum: paper read at the November Conference on 'The Cytopathology of Virus Infection'. Now York: Academy of Sciences.

Banfield, W. G. (1959). Dense granule in the elementary body of molluscum contagiosum. J. Biophys. Biochem. Cytol. 5, 513.

Banfield, W. G. \& Brindley, D. C. (1959). An electron microscopic study of the epidermai lesion of molluscum contagiosum. Ann. N.Y. Acad. Sci. 81, 145.

Banfield, W. G., Bunting, H., Strauss, M. J. \& Melnick, J. L. (1951). Electron micrographs of thin sections of molluscum contagiosum. Proc. Soc. exp. Biol., N.Y., 77, 843.

Banfined, W. G., Bunting, H., Strauss, M. J. \& Melnick, J. L. (1952). The morphology and development of molluscum contagiosum from electron micrographs of thin sections. Exp. Cell Res. 3, 373.

Borysko, E. (1956). Recent developments in methacrylate embedding. I. A study of the polymerization damage phenomenon by phase-contrast microscopy. II. Methods for the sectioning of optically selected single cells, the orientation of the plane of sectioning and the identification of the region of the specimen included in the section. J. Biophys. Biochem. Cytol. 2 (Suppl.), 3, 15.

Charles, A. (1959). An electron microscope study of cornification in the human skin. J. invest. Derm. 33, 65. 
Chardes, A. \& Smiddy, F. G. (1957). The tonofibrils of the human epidermis. J. invest. Derm. $29,327$.

Dourmashkn, R. \& Bernhard, W. (1959). A study with the electron microscope of the skin tumour of molluscum contagiosum. J. Ultrastructure Res. 3, 11.

Dourmashkin, R. \& Duperrat, B. (1958). Observation au microscope électronique du virus du 'Molluscum contagiosum'. C.R. Acad. Sci., Paris, 246, 3133.

Dotrmashkin, R. \& Febvre, H. L. (1958). Culture in vitro sur des cellules de la souche HéLa et identification au microscope électronique du virus du molluscum contagiosum. C.R. Acad. Sci., Paris, 246, 2308.

FuewetT, T. H. \& Tymms, P. (1956). Use of gold sols as an aid to focusing in high-resolution electron microscopy. Nature, Lond. 177, 98.

GaYloRd, W. H. \& Melnick, J. L. (1953). Intracellular forms of pox virus as shown by the electron microscope (vaccinia, ectromelia, molluscum contagiosum). J. exp. Med. 98, 157.

Glauert, Audrey M. \& Glauert, R. H. (1958). Araldite as an embedding medium for electron microscopy. J. Biophys. Biochem. Cytol. 4, 191.

Glauert, Audrey M., Rogers, G. E. \& Glauert, R. H. (1956). A new embedding medium for electron microscopy. Nature, Lond., 178, 803.

GreEn, R. H., Anderson, T. F. \& SMADEL, J. E. (1942). Morphological structure of the virus of vaccinia. J. exp. Med. 75, 651.

Lever, W. F. (1954). Histopathology of the Skin. Philadelphia: J. B. Lippincott Co.

Melnick, J. L., Bunting, H., Banfield, W. G., Strauss, M. J. \& Gaylord, W. H. (1952). Electron microscopy of viruses of human papilloma, molluscum contagiosum, and vaccinia, including observations on the formation of virus within the cell. Ann. N.Y. Acad. Sci. 54, 1214.

Mescon, H., Gray, Margaret \& Moretti, G. (1954). Molluscum contagiosum: a histochemical study. J. invest. Derm. 23, 293.

Morgan, C., Ellison, S. A., Rosw, H. M. \& Moort, D. H. (1954a). Structure and development of viruses as observed in the electron microscope. I. Herpes simplex virus. J. exp. Med. 100, 195.

Morgan, C., Ellison, S. A., Rose, H. M. \& Moore, D. H. (1954b). Structure and development of viruses as observed in the electron microscope. II. Vaccinia and fowl pox viruses. J. exp. Med. 100, 301.

Palade, G. (1952). A study of fixation for electron microscopy. J. exp. Med. 95, 285.

PeTERs, D. (1956). Morphology of resting vaccinia virus. Nature, Lond., 178, 1453.

SELBY, C. C. (1955). An electron microscope study of the epidermis of mammalian skin in thin sections. I. Dermo-epidermal junction and basal cell layer. J. Biophys. Biochem. Cytol. 1, 429.

Takaki, F., Suzuki, T., Yusuda, H., Tagughi, S., Dohr, J. \& Sasao, M. (1957). An electron microseopic study on molluscum contagiosum. J. Tokyo Jikeikai School Med. 4, 60.

WADA, S. (1957). Electron microscopic studies on the molluscum contagiosum virus. (Japanese text.) Virus (Kyoto), 7, 169, 216.

\section{EXPLANATION OF PLATES}

\section{Abbreviations used}

$a . v$. , older stages of virus development; b.p., broken, or ruptured, prickles; c.a., clear area in viroplasm; c.c., cytoplasmic cloud; c.s., cytoplasmic strands; c.w., cell wall-membranes; d.b., dense bodies; f., fibrous material; g.m., granular material; g.t., Golgi, or Golgi-type, structure; h.l., horny layer cells; i.c.s., intercellular structures; k.h., keratohyalin; m., mitochondria; m.s., membranous structures; $n$. , nucleus; $n d$. , nucleoid; n.m., nuclear membrane; no., nucleolus; no.t., nucleolar-type material; p., prickles; par., particulate material; p.c., peripheral cytoplasm; s.m., swollen mitochondria; $t$.f., tonofibrils; u.c., see relevant legend or text; $v$., vesicle, or vesiculate material; v.m., viral membranes; v.n., vesiculation in the extra-nucleolar nucleoplasm; v.no., vesiculation in the nucleolus; v.p., presumed virus particles; $x . a$. , unidentified structure; x.c., nuclear inclusion of uncertain nature; x.v., extracellular viral particles; $y . v$., young stages of virus development.

The small dense dots, usually in clumps or chains, seen in some of the figures are particles of gold sol, about $150 \AA$. diameter, used as an aid to focusing (Flewett \& Tymms, 1956). 


\section{Plate 1}

Fig. 1. Araldite-embedded material showing the upper part of a basal cell. The cytoplasm is abnormal, as explained in the text. The vesicle $(v$.$) has an apparently hollow centre en-$ closed by an electron-dense wall lined by less electron-dense material. $x$.a. is a structure of uncertain nature which may be akin to the structure (m.s.). $\times 21,000$.

Fig. 2. Araldite-embedded material showing the mature molluseum body. The remnants of the cell cytoplasm can be seen centrally and peripherally in both cases containing imbedded virus particles. The nucleus remnant contains no virus. Although the cell is packed with virus very little extracellular virus (x.v.) is seen, that shown on the upper left of the figure being associated with an apparent breakage in the peripheral cytoplasm. (v.p.) are presumed virus particles in horny layers which, as a whole, must be regarded as uninfected. $\times 5500$.

\section{Plate 2}

Fig. 3. Methacrylate-embedded material showing the very abnormal nucleus with vesiculation of the nucleolus and extra-nucleolar nucleoplasm $(v . n$.$) . The particulate material (no.t.) is$ probably nucleolar-type material. The swollen and disorganized mitochondria are arranged at the periphery of an area of cytoplasm (u.c.) which shows fibrous material $(f$.) and is very different from the vesiculated cytoplasm at the bottom. $\times 27,000$.

Fig. 4. Araldite-embedded material showing details of the peripheral cytoplasm of an infected cell in which mature virus is seen. The significance of the particulate and vesiculate structures is not known. On the upper third of the figure, separated from the infected cell by a cell wall-membrane, is the flattened outline of part of a normally cornifying cell containing keratohyalin. Intercellular structures of unknown nature are present (i.c.s.), as also are the prickles and tonofibrils. $\times 27,000$.

\section{Plate 3}

Fig. 5. Methacrylate-embedded material. The much-indented nucleus has a very abnormal appearance, and the nucleolus contains one particularly large vesicle with apparently a central body. The extra-nucleolar nucleoplasm also appears vesiculated, and contains nucleolustype material (no.t.) and two inclusions (x.c.) of very similar appearance to cytoplasmic clouds. The embedding of the groups of older virus particles appears to be imperfect, and this may in fact be the case, or it may be a cutting artifact, a slight localized tearing caused by the hardness of the particles. $\times 14,500$.

Fig. 6. Methacrylate-embedded material showing development details of the dense bodies in the nucleus; the arrows indicate only the less developed clusters. $\times 81,000$.

\section{Plate 4}

Fig. 7. A: methacrylate-embedded material. The eccentric nucleus and apparently uninfected peripheral cytoplasm are easily distinguishable. Virus development is now spreading through the whole of the central cytoplasmic mass. The central part of the figure is enlarged in fig. 8A, in connexion with which the development stages of the virus are described. $\times 13,000$. B : methacrylate-embedded material showing the later stages (7 and 8 ) of virus development discussed in the text. $\times 45,000$. C: an enlargement of stage 7 shown in fig. $7 \mathrm{~B}$. $\times 81,000$. D: double-membrane structure. The usual coarse granular contents are present only sparsely in this illustration. $\times 81,000$. E, and $F$ : viral particles remarked upon in the text. E, $\times 81,000 ; \mathrm{F}, \times 87,500$. G: a particle of possibly a second type of virus, the central region of which appears to be related to the double-membrane structures. $\times 72,000$.

\section{Plate 5}

Fig. 8. A: enlargement of the central area of fig. 7 A showing the various development stages $(1$ to 6$)$ of the virus. The particles $(a),(b)$ and $(c)$ are discussed in the text. $\times 46,000$. B : methacrylate-embedded material taken from a 13-year-old girl, showing the hollow nature of the mature virus, located in the oedematous cytoplasm. Younger stages can be seen developing in the sparse cytoplasm towards the left of the figure. $\times 71,000 . \mathrm{C}$, and D: araldite-embedded material referred to in the text. $\times 81,000$. E: shows a virus particle with the nucleoid separated from the rest of the viroplasm by a clear region (c.a.). $\times 81,000$. 

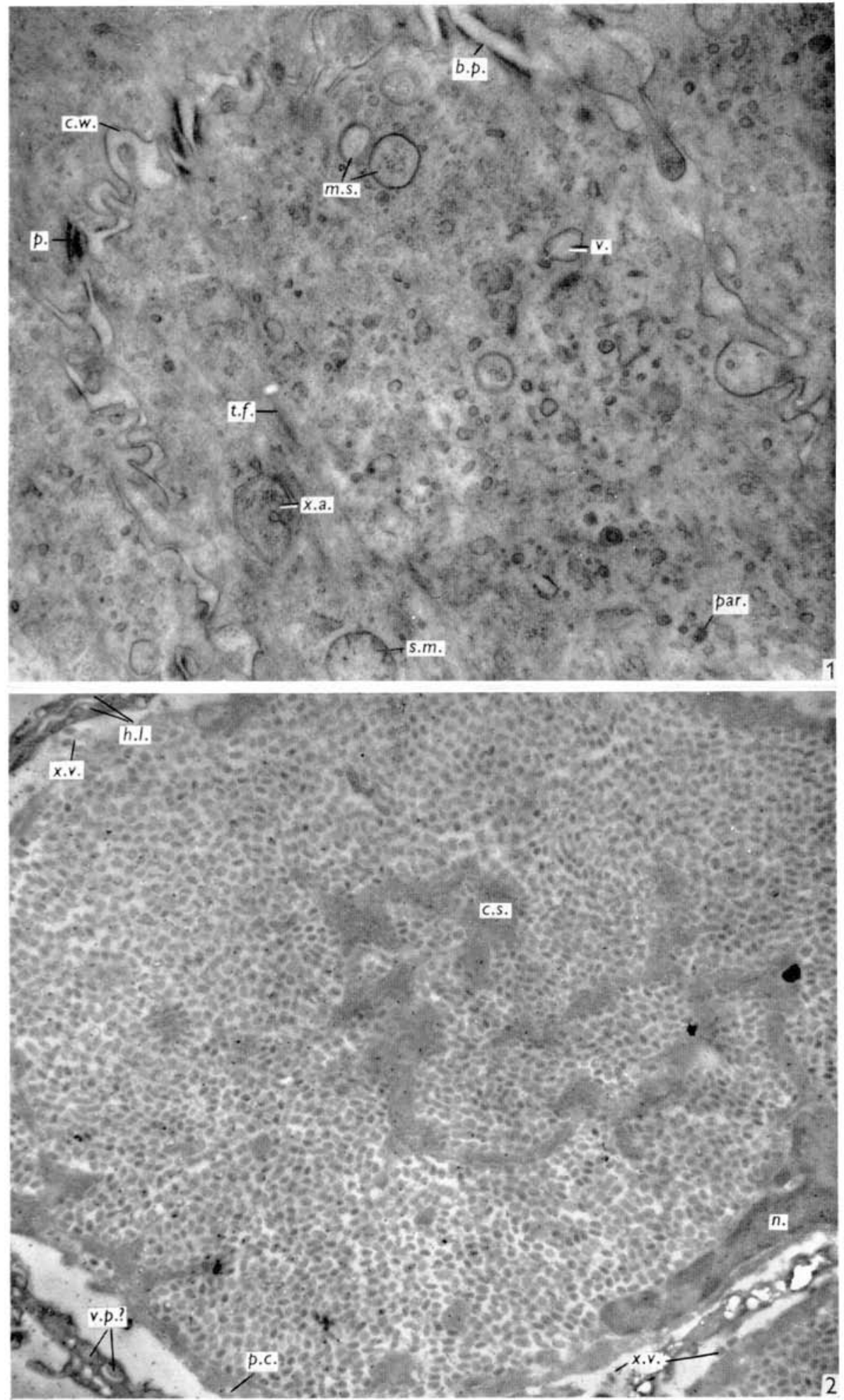

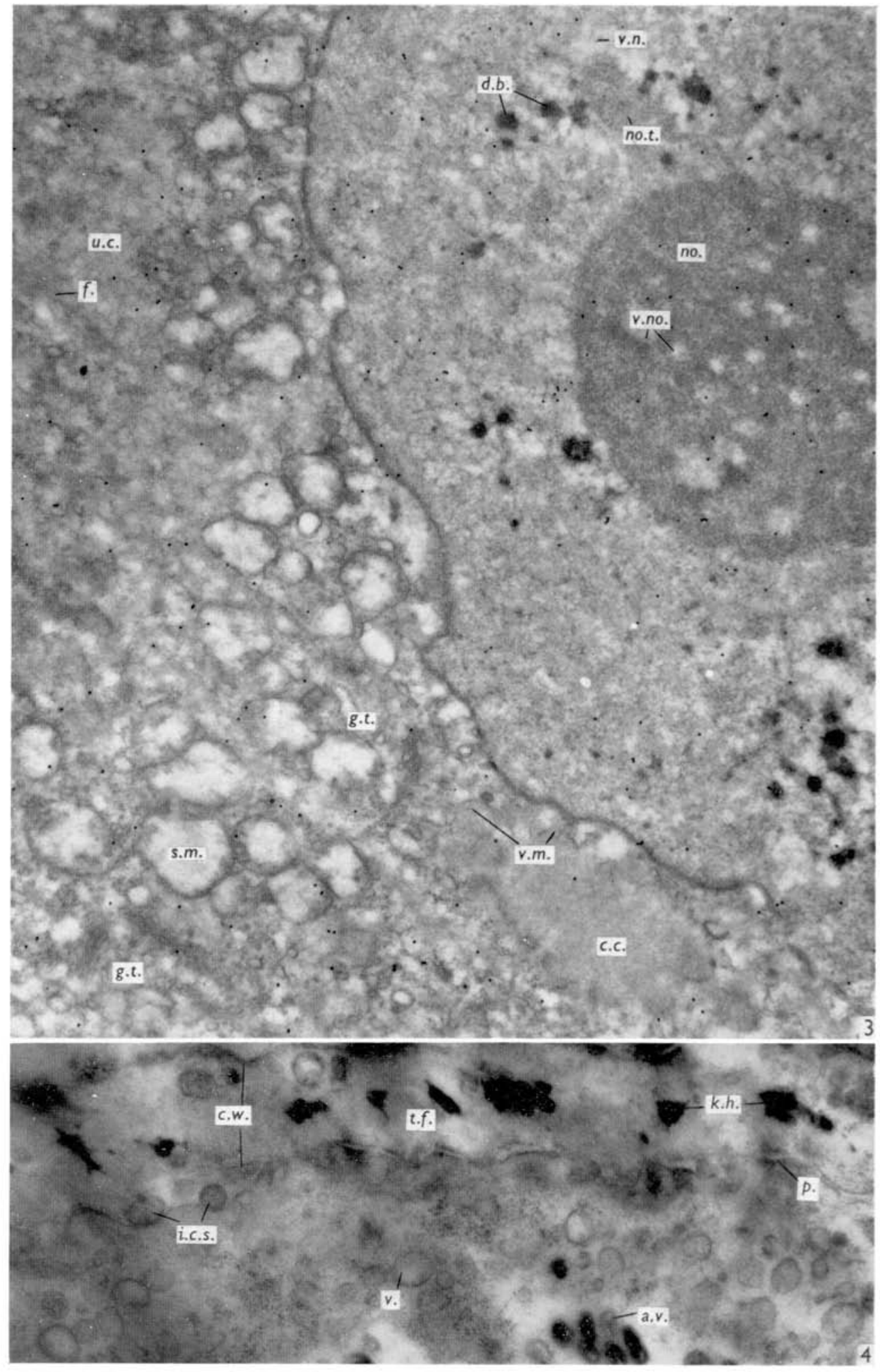


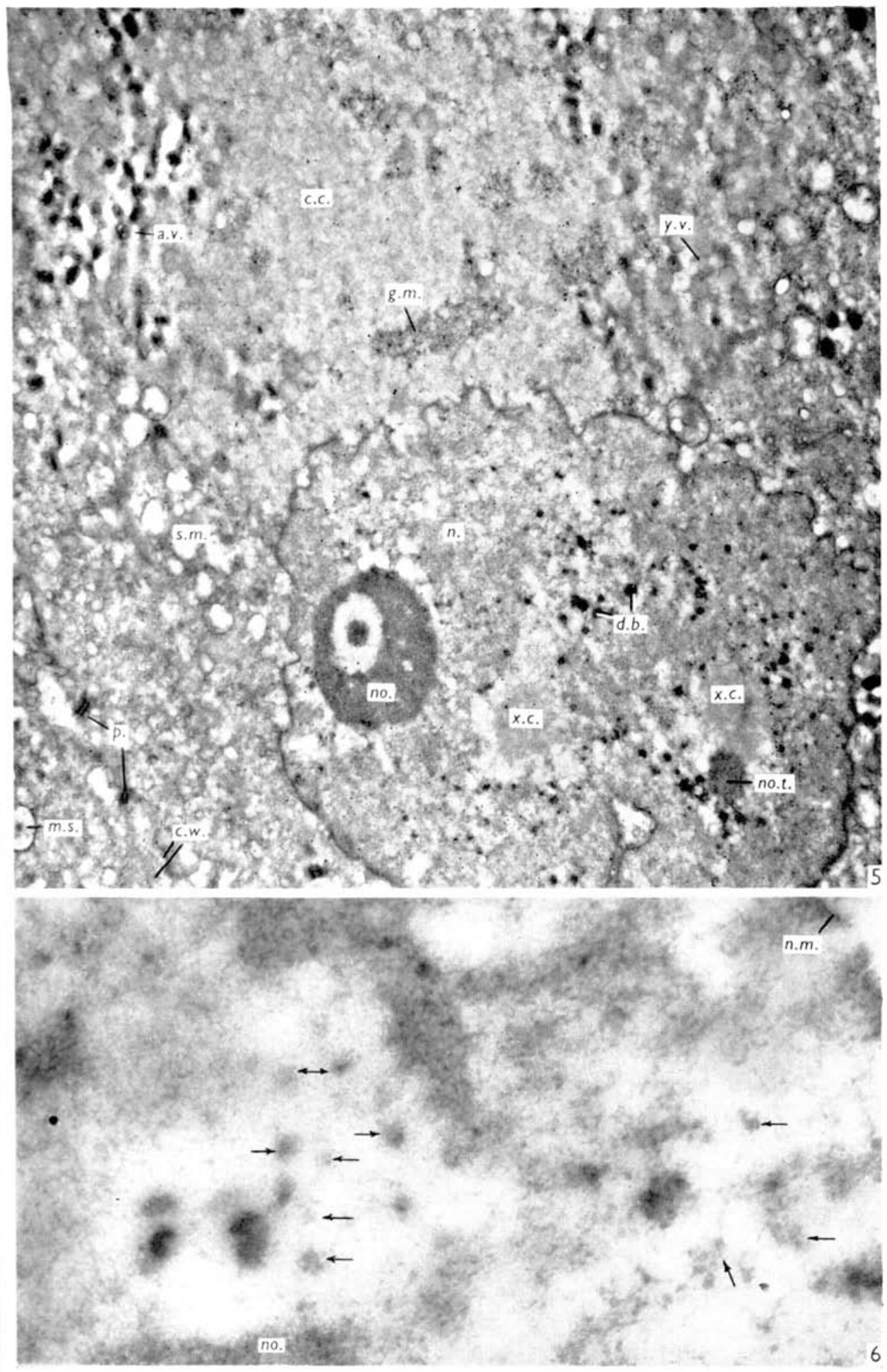




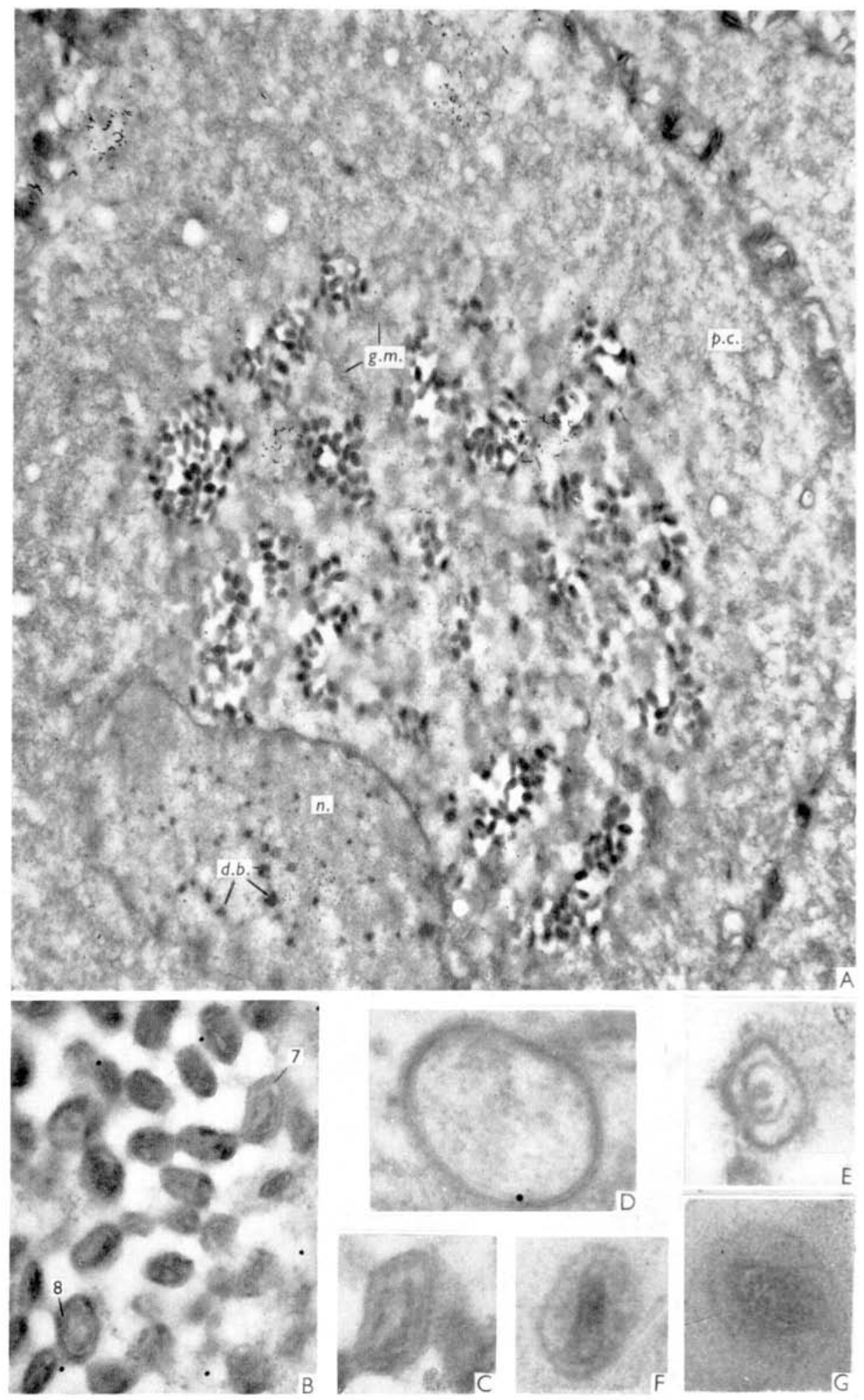




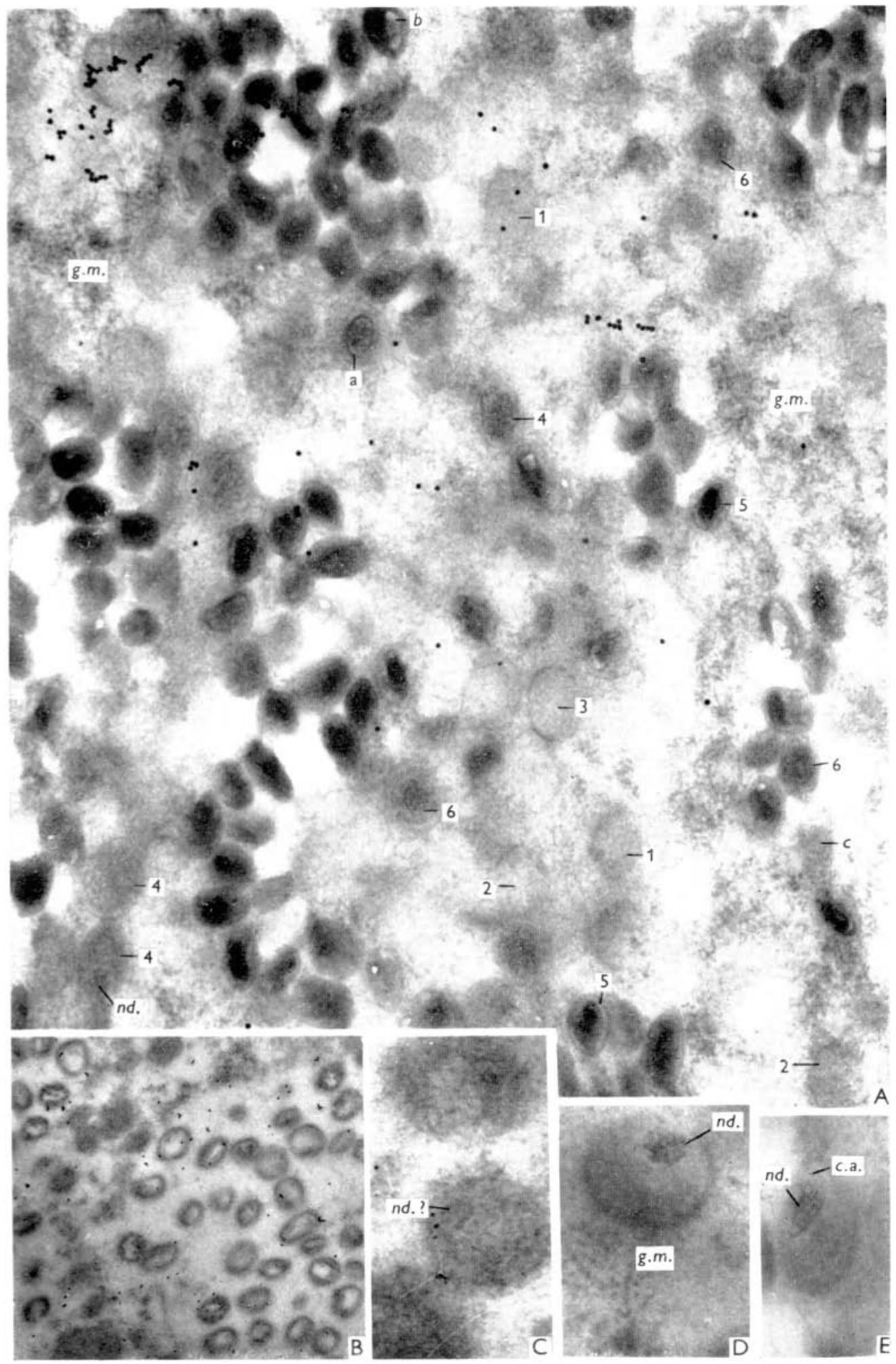

